\title{
3D Observation of Micro-cracks as Cleavage Fracture Initiation Site in Ferrite-pearlite Steel
}

\author{
Yoshiki NEMOTO, ${ }^{1)}$ Kazuki SHIBANUMA, ${ }^{1 *}$ Katsuyuki SUZUKI, ${ }^{2)}$ Sunao SADAMATSU, ${ }^{3)}$ Yoshitaka ADACHI \\ and Shuji AlHARA ${ }^{11}$
}

1) Department of Systems Innovation, The University of Tokyo, 7-3-1 Hongo, Bunkyo-ku Tokyo, 113-8656 Japan.

2) Research into Artifacts, Center for Engineering, The University of Tokyo, 5-1-5 Kashiwanoha, Kashiwa, Chiba, $277-8568$

Japan. $\quad 3)$ Department of Mechanical Engineering, Kagoshima University, 1-21-24, Kohrimoto, Kagoshima, $890-8580$ Japan.

(Received on October 26, 2016; accepted on December 14, 2016)

\begin{abstract}
In order to establish a basis to predict fracture toughness of ferrite-pearlite steel, a two-stage investigation was performed. A 3D observation was first performed to characterize the relationship between microcracks and microstructures using a serial sectioning technique. Two types of micrographs before and after nital etching were taken to obtain 3D images of micro-cracks and microstructures, respectively. As a result of superposition of both the 3D images, it is found that a micro-crack initiated at ferrite-pearlite boundary and then propagated into pearlite grain. It is also found under the ellipse approximation of the microcracks that the distribution of major axis of micro-crack was close to that of the ferrite grain diameter and the distribution of miner axis was an intermediate between those of ferrite grain diameter and pearlite band thickness. Based on the results, we then proposed a 3D model on micro-crack with an oblate spheroid assumption of pearlite grain to quantitatively relate microstructures of ferrite-pearlite steel to the fracture stress. It was shown that the fracture stresses corrected by the proposed 3D model were 20-30\% less than those evaluated by the conventional $2 \mathrm{D}$ model. It is expected to be caused by the reason that the accuracy of the conventional 2D model was less than that of the proposed 3D model based on the detailed 3D observation because the conventional model is based on the simplified assumption of 2D micro-crack in the 3D microstructure. Therefore, we can give a valuable basis to develop an accurate fracture toughness prediction model based on the detailed 3D observation.
\end{abstract}

KEY WORDS: fracture toughness; micro-crack; 3D serial sectioning; fracture stress; ferrite-pearlite steel.

\section{Introduction}

Steel is one of the most commonly used structural materials. Fracture toughness is one of the most important fundamental mechanical properties of the steel, so that there have been a lot of studies to understand and improve it. It is widely known that fracture toughness is strongly affected by microstructures in steels. ${ }^{1,2)}$ However, the quantitative relationship between the fracture toughness and the microstructures has not been sufficiently clarified. ${ }^{3-6)}$ It is therefore significant to establish a theory to quantitatively predict the fracture toughness in order to effectively develop the material design of steels.

One of the major reasons of the difficulty for quantifying the influence of microstructures on fracture toughness is caused by the fact that there is a scatter of the fracture toughness as intrinsic nature. ${ }^{7)}$ Pineau et al. proposed a model to evaluate a scatter of cleavage fracture toughness based on the weakest-link theory, called as the Beremin model. $^{8-10)}$ The effectiveness of the Beremin model has been widely known ${ }^{11-13)}$ and several modifications were proposed

\footnotetext{
* Corresponding author: E-mail: shibanuma@struct.t.u-tokyo.ac.jp DOI: http://dx.doi.org/10.2355/isijinternational.ISIJINT-2016-607
}

in the past, ${ }^{14-19)}$ because it enables a quantitative evaluation of the scatter and size effect of structure on fracture toughness. However, these models are generally not intended to quantitatively predict fracture toughness caused by the microstructural factors, because they adopted the parameters for adjusting the experimental results of fracture toughness tests.

Some stochastic models to predict the influence of the microstructures on the fracture toughness were proposed by taking into account additional meanings of the microstructural factors on the Beremin model. ${ }^{20,21)}$ The predictions of all the models were however limited to a unique steel, so that the applicability to the steels having different distributions of microstructures was not covered.

Shibanuma et al. recently proposed a prediction model of cleavage fracture toughness of ferrite-cementite steels, ${ }^{22,23)}$ based on the microscopic fracture initiation process. ${ }^{3,24-26)}$ As a result of application of the model to the fracture toughness test of the steels having various size of microstructures, the prediction results showed good accuracy with the actual experimental ones. The model was limited in an application to the steels having simple ferrite-cementite microstructures, so that the applicability of the model particularly to the steels actually used is a new issue to be solved in the future. 
Ferrite-pearlite steel is one of the most widely used steels. It has been generally known that a cleavage fracture is initiated at the pearlite in a ferrite-pearlite steel. ${ }^{27-30)}$ An example of SEM images of the fracture initiation site in pearlite obtained by a fracture toughness test is shown in Fig. 1. Hiraide et al. developed a model to predict fracture toughness of the ferrite-pearlite steel, ${ }^{31)}$ as a modification of the model proposed by Shibanuma et al. ${ }^{22,23)}$ The model was based on the microscopic fracture process composed of three stages: (I) Micro-crack formation in shear at pearlite grain; (II) Crack propagation into ferrite matrix; (III) Crack propagation across ferrite grain boundary, as shown in Fig. 2. The prediction results successfully simulated the dependence of fracture toughness on temperature for a specified steel. However, the influence of geometric factors of microstructures, such as grain size and volume fraction of pearlite, on fracture toughness could not be quantitatively explained in

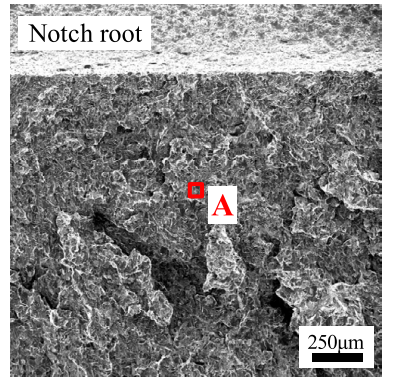

(a) Cleavage fracture intiation site

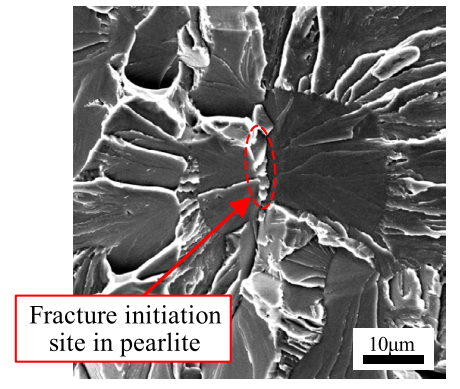

(b) Close-up of A
Fig. 1. Cleavage fracture initiation site obtained by fracture toughness test. (Online version in color.)

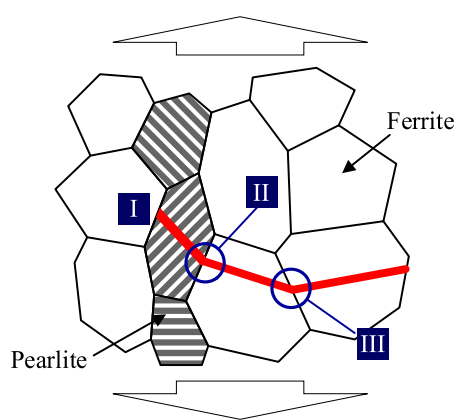

Fig. 2. Cleavage fracture initiation process of ferrite pearlite steel. (Online version in color.)

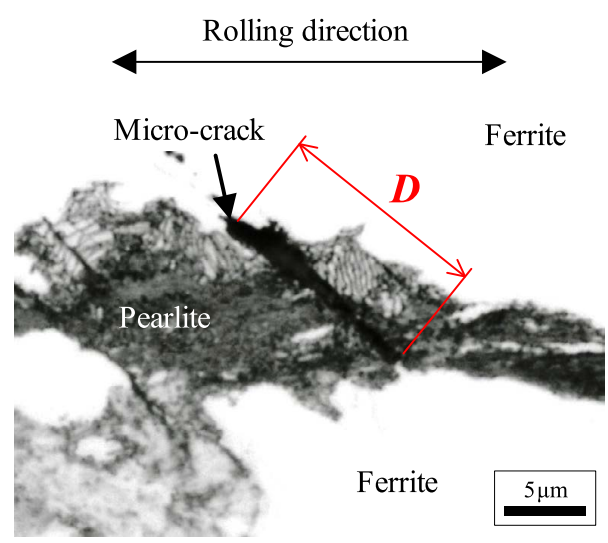

Fig. 3. Micro-crack modeling based on $2 \mathrm{D}$ observation (the crack shape is assumed as a circle with diameter $D) .{ }^{31)}$ (Online version in color.) the model. In addition, the model was developed based on the limited knowledge obtained by two-dimensional (2D) observations. That is, the shape of micro-crack was simply assumed as a circle whose diameter is corresponding with the thickness of pearlite band, as shown in Fig. 3.

It is therefore necessary to modify the formulation of fracture process taking into account parameters describing microstructures in more detail. In particular, in order to correct the accuracy of the prediction model, it is essential to accurately study three-dimensional (3D) geometrical relationship between the micro-crack and microstructures of the ferrite-pearlite steels.

The technology of three-dimensional (3D) serial sectioning has recently shown remarkable development. It can promote deeper understanding in the morphology of materials than that of the conventional 2D observation. ${ }^{32-38)}$ However, there has not been a study to quantify the relationship between the shapes of micro-crack and microstructures in the ferrite-pearlite steels.

According to the above background, this paper presents a two-stage investigation in order to establish a basis to predict cleavage fracture toughness of ferrite-pearlite steels: (i) A characterization of the relationship between micro-cracks and microstructures based on the detailed 3D serial sectioning observation; (ii) A proposal of model to quantitatively relate the 3D geometric influence factors of microstructures to the fracture stress, which is one of the most essential factors to determine the fracture toughness.

\section{Test Steels}

This section shows foundational mechanical properties and quantifications of microstructures of employed ferritepearlite steel.

The chemical composition of the steel is shown in Table 1. The employed steel was made as a sample based on the typical low carbon steel. After hot-rolling, ferrite-pearlite structures were made by combination of normalizing and cooling as shown in Table 2. Representative mechanical properties of the steel are shown in Table $\mathbf{3}$.

A sample was extracted from the thickness center of the steel plate. The cross section of the sample perpendicular

Table 1. Chemical compositions of tested steels (mass\%).

\begin{tabular}{ccccccc}
\hline $\mathrm{C}$ & $\mathrm{Si}$ & $\mathrm{Mn}$ & $\mathrm{P}$ & $\mathrm{S}$ & $\mathrm{Al}$ & $\mathrm{N}$ \\
\hline 0.18 & 0.15 & 0.99 & $<0.002$ & 0.0005 & 0.019 & 0.0008 \\
\hline
\end{tabular}

Table 2. Heat treatment condition and microstructure.

\begin{tabular}{|c|c|c|c|}
\hline \multicolumn{3}{|c|}{ Normalizing } & \multirow{2}{*}{ Cooling } \\
\hline Rolling & Heating & Holding & \\
\hline Hot rolling & $900^{\circ} \mathrm{C}$ & $1 \mathrm{~h}$ & Air \\
\hline
\end{tabular}

Table 3. Representative mechanical properties.

\begin{tabular}{ccc}
\hline \multicolumn{2}{c}{ Tencile property at room temperature } & Charpy impact property \\
\hline Yield stress $[\mathrm{MPa}]$ & Tensile strength $[\mathrm{MPa}]$ & $\mathrm{vTrS}\left[{ }^{\circ} \mathrm{C}\right]$ \\
\hline 241 & 527 & -8.6 \\
\hline
\end{tabular}


to the rolling direction was then polished and etched by $2 \%$ nital. Figure 4 shows the obtained optical micrograph of the test steel.

After polishing by cross section polisher, the surfaces of 4 $\mathrm{mm} \times 2 \mathrm{~mm}$ were measured by the EBSD method. ${ }^{39)}$ Grain boundary was defined as the boundary where misorientation was larger than $5^{\circ}$. To exclude pearlite grains, we carried out a cleanup processing where a threshold of image quality (IQ) was defined as the highest $25 \%$. An inverse pole figure map with IQ of the raw data and an approximate ferrite grain map were obtained as the results of the cleanup processing are shown in Fig. $\mathbf{5}$.

A shape of ferrite grain was approximated as sphere. The distribution of the $2 \mathrm{D}$ grain diameter was converted into $3 \mathrm{D}$ data based on the quantitative stereology ${ }^{40)}$ Figure 6 shows the converted cumulative probability distributions of the ferrite grain diameter $d$.

The pearlite band thickness $t$ was measured by image analysis for the optical micrographs. The image obtained by optical microscope observation was binarized as shown in Fig. 7(a). The area of 4 px $(2.08 \mu \mathrm{m})$ width was then extracted with $50 \mathrm{px}(26.04 \mu \mathrm{m})$ interval in pearlite band direction. The thickness $t$ was evaluated as the height of the equivalent rectangle of the measured area of $4 \mathrm{px}$ in width. A schematic diagram of the measurement process is shown in Fig. 7(b). The larger pearlite grain has the higher possibility to be measured by the above process. Therefore,

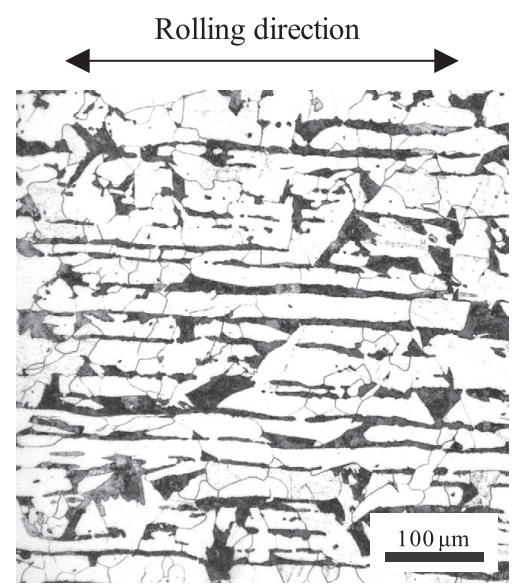

Fig. 4. Micrograph of the test steel (polished and etched by $2 \%$ nital).

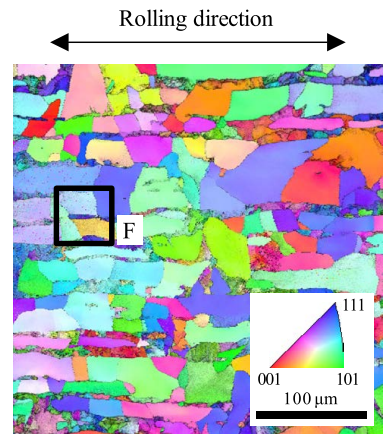

(a) Inverse pole figure map with image quality

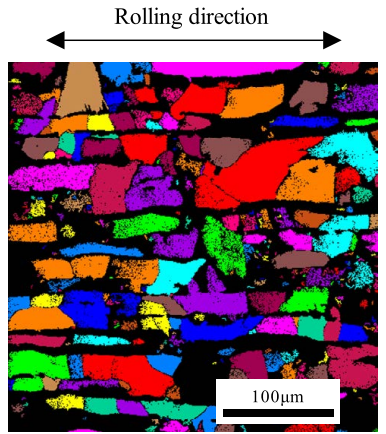

(b) Approximated grain map by cleanup processing to remove pearlite
Fig. 5. EBSD method to obtain distribution of 2D ferrite grain diameter. (Online version in color.)

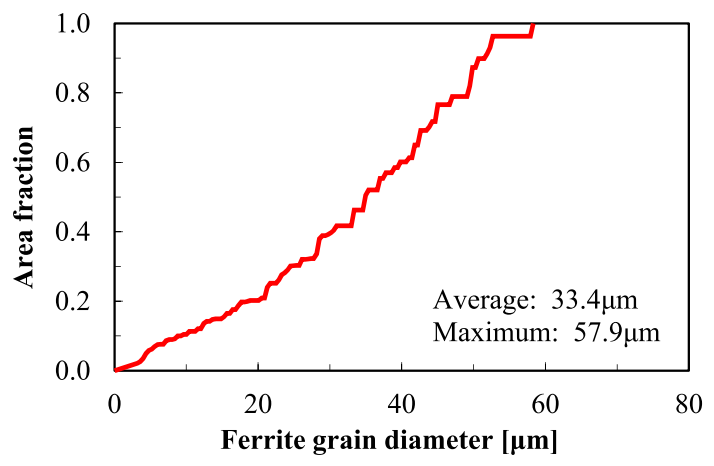

Fig. 6. Distribution of ferrite grain diameter $d$. (Online version in color.)

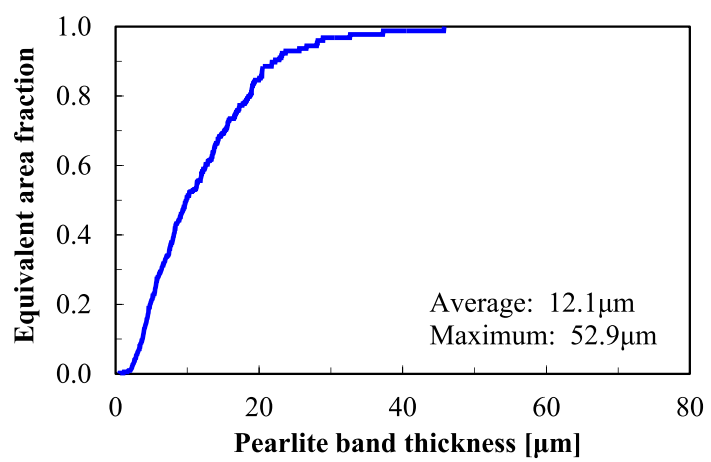

Fig. 8. Distribution of pearlite band thickness $t$. (Online version in color.)

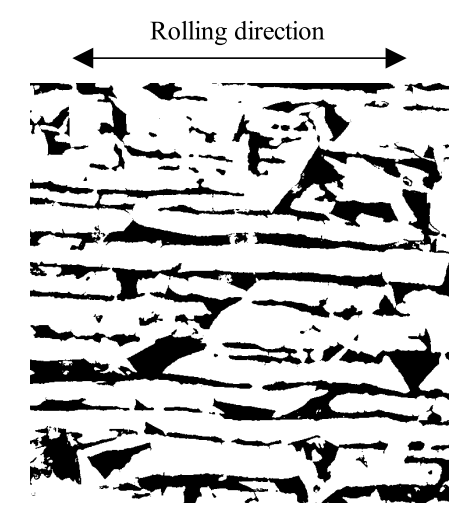

(a) Binarized optical microgragh

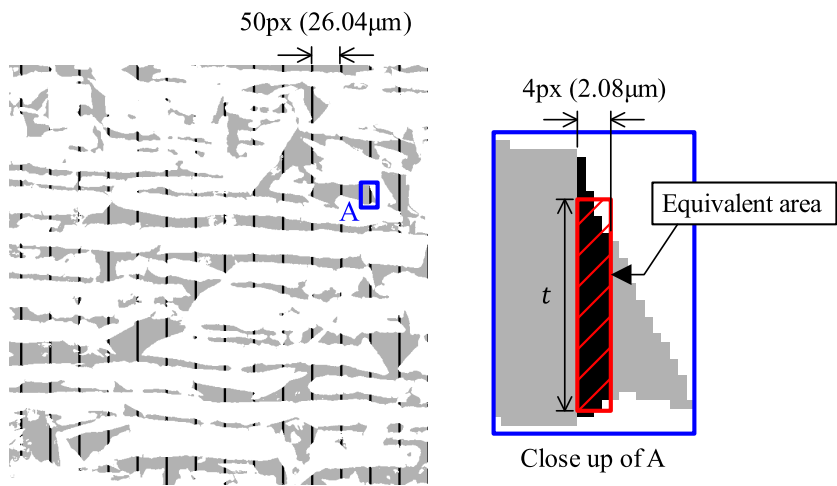

(b) Pearlite band measurement

Fig. 7. Schematic diagram of measurement method of pearlite grain thickness $t$. (Online version in color.) 
the measured data was weighted by the inverse of thickness under the assumption that the aspect ratios of pearlite grains were approximately equivalent. The obtained distribution of the pearlite band thickness $t$ is shown in Fig. 8. It is noted that the vertical axis of the graphs in Fig. 8 denotes the cumulative probability of equivalent area fraction, which was defined as the cumulative probability of number weighted by a square of pearlite grain thickness.

\section{Characterization of the Relationship between Micro- cracks and Microstructures}

In order to accurately predict cleavage fracture toughness of ferrite-pearlite steels, it is significant to clarify the geometrical relationship between micro-cracks and microstructures. In this section, a foundational characterization of the relationship between micro-cracks and microstructures of ferrite pearlite steel is presented by using a 3D serial sectioning observation technique.

\subsection{Tensile Test Using Notched Specimen}

In order to make a sample to observe residual microcracks, it is required to conduct an experiment where the fracture condition in the stage (I) is satisfied but that of the stage (II) is not satisfied (see the process of the cleavage fracture initiation as shown in Fig. 2. The stage (I) of the fracture process is a micro-crack nucleation in shear at pearlite grain, which is approximately described as strainbased fracture. ${ }^{27-30)}$ On the other hand, the stage (II) of the fracture process is crack propagation into ferrite matrix, which is approximately described as stress-based fracture. ${ }^{3)}$ Based on the above consideration, the quasi-static tensile test was conducted using circumferential notched round bar specimen as shown in Fig. 9.

The test temperature was $-120^{\circ} \mathrm{C}$ and the loading rate was $2 \mathrm{~mm} / \mathrm{min}$. A gage displacement was determined so

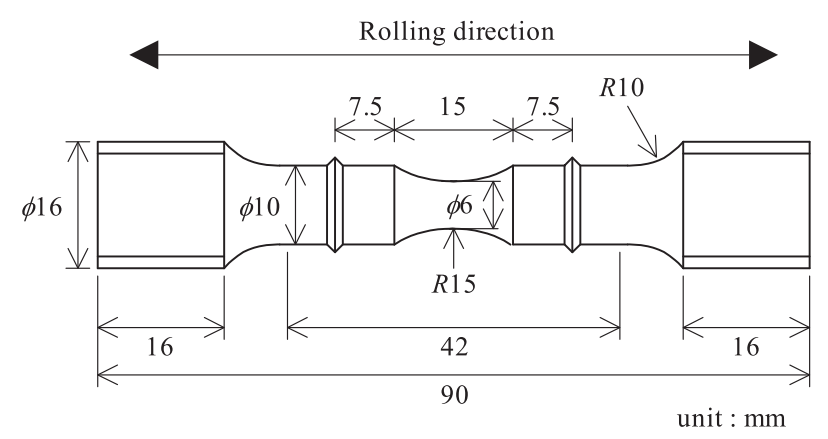

Fig. 9. Circumferential notched specimen. that the equivalent plastic strain at the minimum cross section corresponds to 0.7 because it is necessary to generate micro cracks without rupturing the specimen. This condition was determined by a preliminary elasto-plastic finite element analysis using Abaqus. ${ }^{41)}$ The finite element model considered axial and plane symmetries. Figure 10 shows the mesh of the finite element model. Figure 11 shows the numerical results of the equivalent plastic strain field and deformation of the specimen.

After the equivalent plastic strain reached 0.7, the load was released. The specimen was cut in the axis direction and then an observation sample of $10 \mathrm{~mm}$ in length was produced at the center of specimen.

\subsection{D Serial Sectioning Observation}

3.2.1. Procedure of 3D Serial Sectioning Observation

After the tensile test, micro-cracks in the specimen were measured by a $3 \mathrm{D}$ serial sectioning observation technique. We employed Genus_3D, which is a full-automatic serial sectioning equipment. ${ }^{\overline{4} 2}$ Figure 12 shows the architecture of Genus_3D. Micrographs before and after 1\% nital etching were taken in the serial sectioning procedure. In the following descriptions, the observations on the non-etched and etched surfaces are named as Observation (1) and Observation (2), respectively. A flowchart of the serial sectioning procedure is shown in Fig. 13.

Optical micrographs of 175 sections were obtained at every step of $0.745 \mu \mathrm{m}$ in depth for polishing per section in both Observation (1) and Observation (2). As a result, the common field of view for the micrographs was $3190 \mu \mathrm{m} \times$ $2400 \mu \mathrm{m}$ and the accumulated serial sectioning depth was $129.6 \mu \mathrm{m}$ in total.

Building of 3D images of micro-cracks and microstructures were performed by Avizo. ${ }^{43)}$ Figure 14 shows a schematic of the procedure to build the $3 \mathrm{D}$ images. The images of the non-etched sections obtained by Observation (1)

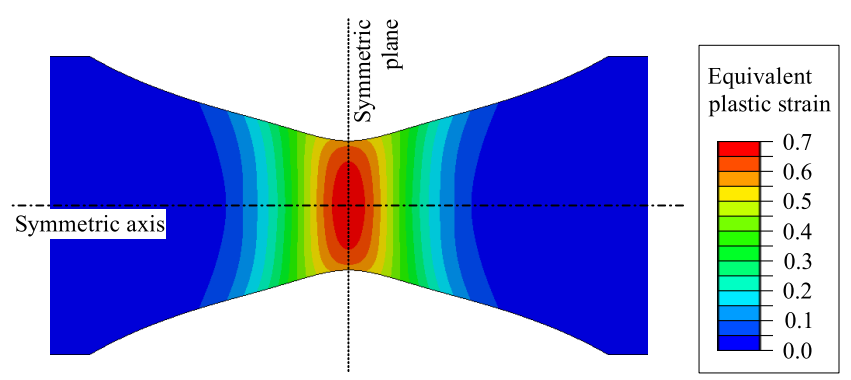

Fig. 11. Equivalent plastic strain and deformation of the specimen obtained by finite element analysis $\left(-120^{\circ} \mathrm{C}\right)$. (Online version in color.)

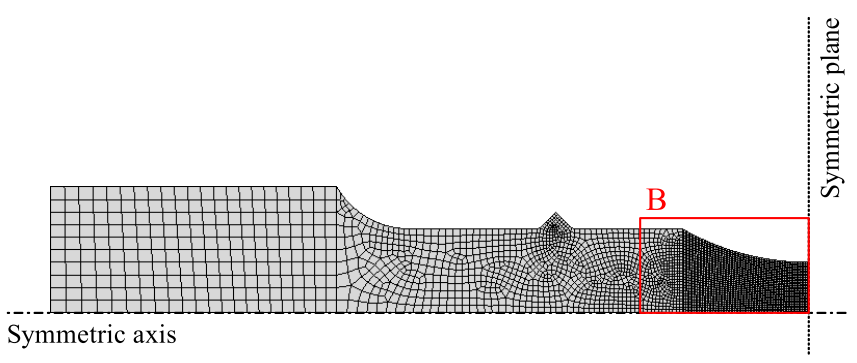

(a) Whole model

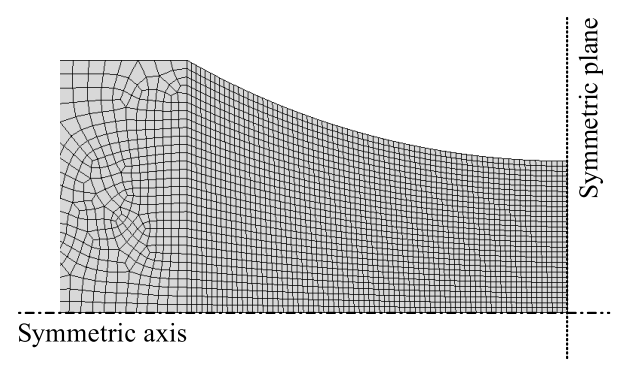

(b) Close up of B

Fig. 10. Finite element mesh of the notched specimen. (Online version in color.) 


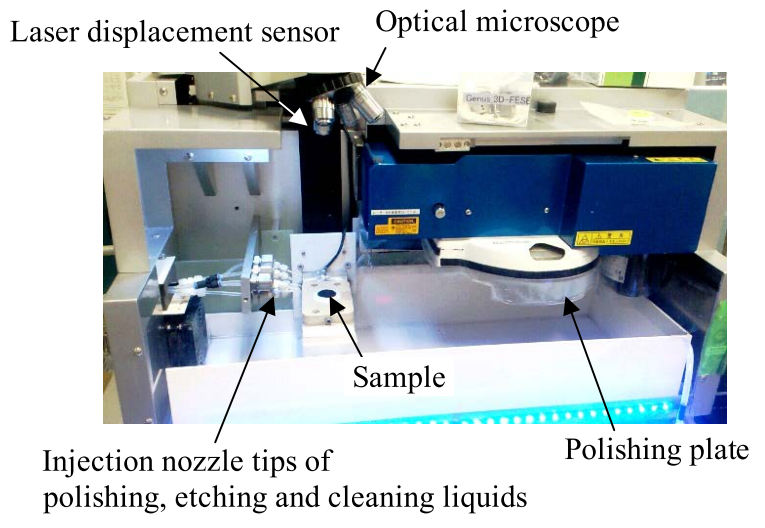

Fig. 12. Architecture of Genus_3D. (Online version in color.)

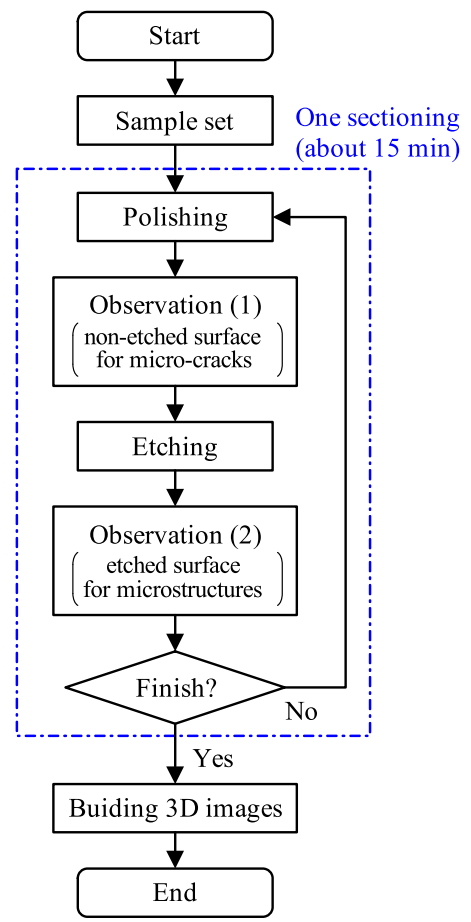

Fig. 13. Flowchart of serial sectioning procedure. (Online version in color.)

were used to build 3D images of micro-cracks. The images of the etched sections obtained by Observation (2) were used to build 3D image of microstructures. Both the images were first cleaned up to remove polishing flaws, voids and inclusions. The respective 3D images of micro-cracks were independently built by the extracted serial sectioning images obtained by Observation (1). The micro-cracks of less than $10 \mu \mathrm{m}$ in length cannot be obtained due to observation accuracy. As a result, 42 micro-cracks with entire shape were obtained as 3D images. On the other hand, the 3D images of microstructures were directly built by using the cleaned up serial sectioning images obtained by Observation (2).

In order to clarify micro-crack initiation sites, 3D images of micro-cracks and microstructures were superposed. Figure 15 shows an example of a perspective view of micro-crack in pearlite, which is the close-up of " $E$ " on the cross section of 3D structural image in Fig. 14. The reason of the crack opening is expected to be due to plastic deformation after the crack forming.

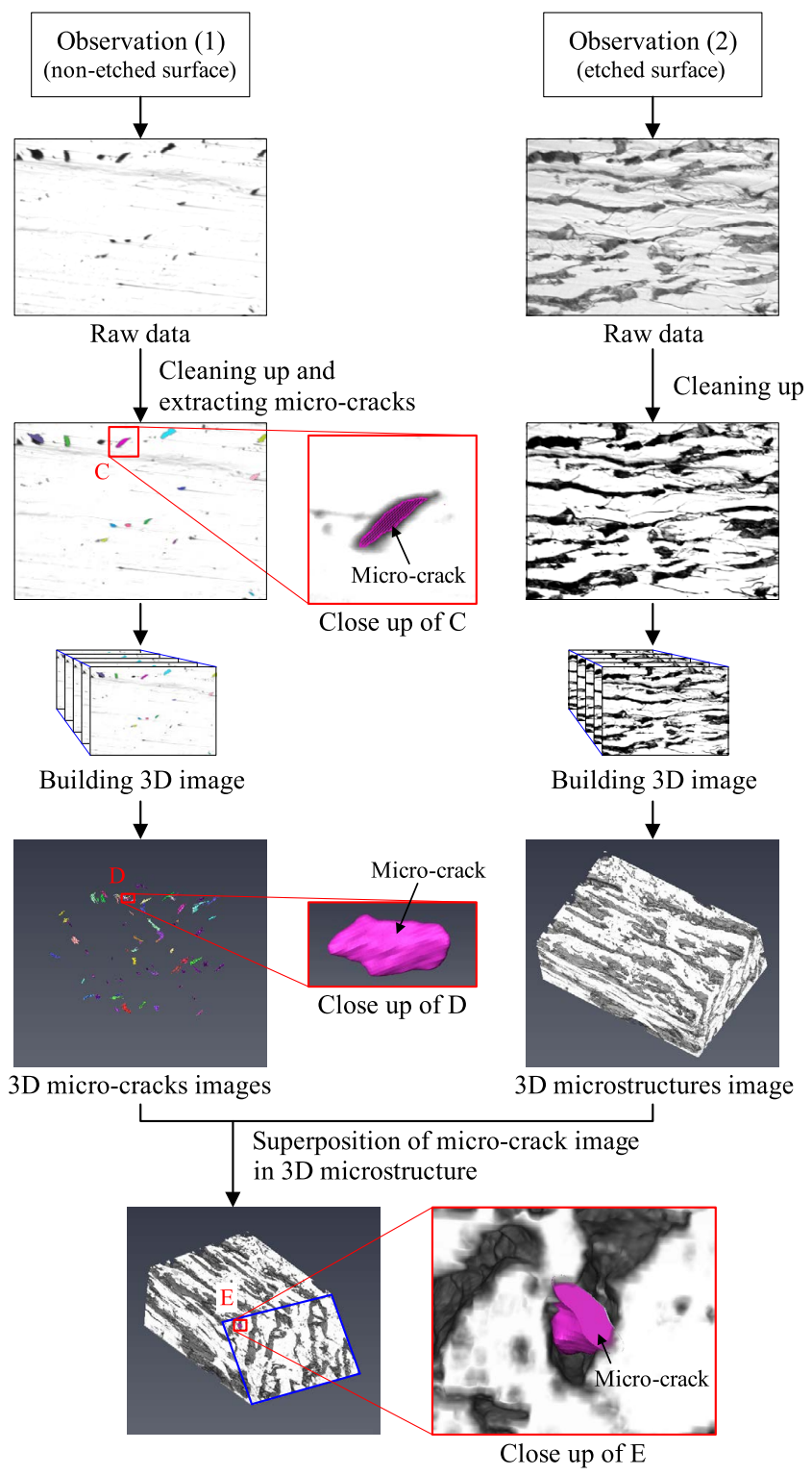

Fig. 14. Procedures to obtain 3D images of micro-cracks and microstructures. (Online version in color.)

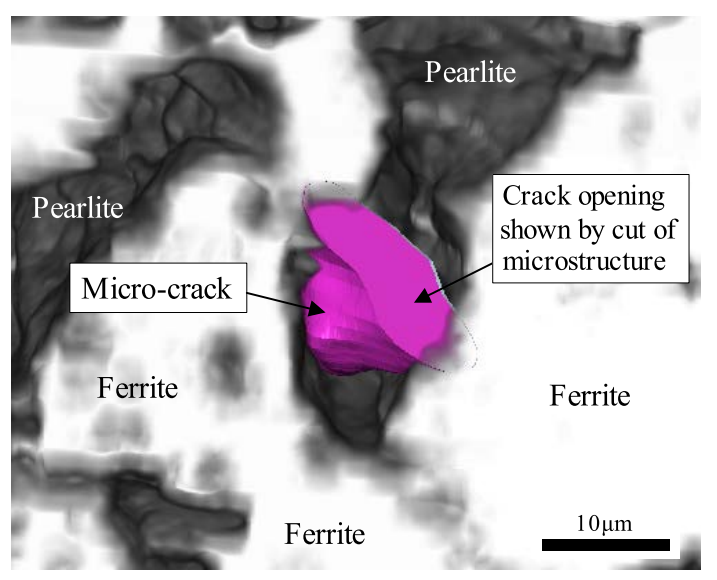

Fig. 15. Perspective view of micro-crack formed in pearlite (Close up of E in Fig. 14). (Online version in color.)

\subsubsection{Results of Formation of Micro-crack}

From the results of 3D superposed image, it is clearly found that all of the observed micro-cracks were formed inside pearlite bands. In addition, the number of 38 (90.5\%) 
observed micro-cracks among 42 observed micro-cracks in total were across pearlite bands. Furthermore, the other 4 were not across the pearlite bands but all the micro-cracks in pearlite were commonly formed adjacent to the boundaries between ferrite and pearlite. It is therefore consequently found that the micro-crack initiates at the ferrite-pearlite boundary and then stably propagates though the inside of the pearlite grain. The results is coincident with the conventional knowledge that the first stage of the cleavage fracture initiation process is the micro-crack formation in shear at pearlite grains, as shown in the stage (I) in Fig. 2.,27-30)

\subsubsection{Characterization of Micro-crack}

An example of a perspective view of micro-cracks is shown in Fig. 16, which is the same micro-crack in Figs. 14 and 15 . In order to characterize micro-cracks, the shape of micro-crack is approximated to be an ellipse. The distributions of measured major axis $a$ and minor axis $b$ of the ellipses are shown in Fig. 17, together with those of the ferrite grain diameter $d$ and the pearlite band thickness $t$ shown in Figs. 6 and 8. It is noted that the vertical axis of the graphs in Fig. 17 denotes the cumulative probability of equivalent area fraction. The results shows that the distribution of $a$ is close to that of $d$ except in the range of less than $10 \mu \mathrm{m}$ in length, where the micro-cracks could not be measured due to the observation accuracy. The results also shows that $b$ was distributed between the $d$ and $t$.

The cumulative probability distribution of aspect ratio of the measured micro-cracks, i.e., $b / a$, is shown in Fig. 18. The representative values of $b / a$ for $5 \%, 50 \%$ and $95 \%$ cumulative probabilities are shown in Table 4. The results showed that the aspect ratio $b / a$ was distributed in a wide

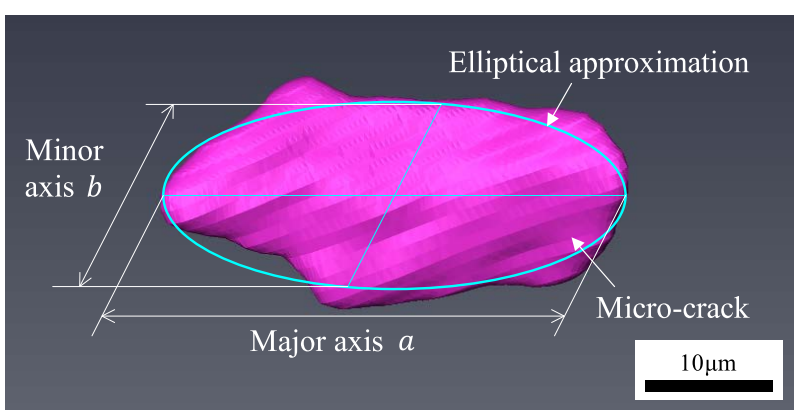

Fig. 16. Perspective view of micro-crack and its elliptical approximation (Close up of D in Fig. 14). (Online version in color.)

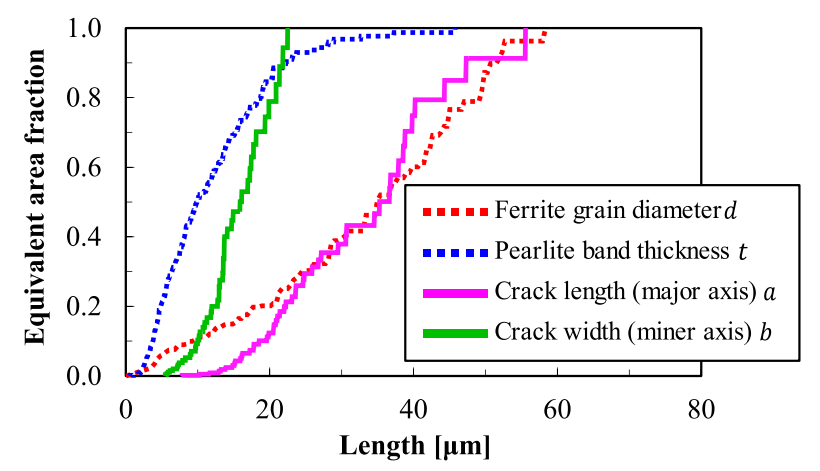

Fig. 17. Distributions of measured crack length and width together with those of ferrite grain diameter and pearlite band thickness. (Online version in color.) range.

\subsubsection{Applicability of the Characterization}

Although it was difficult accurately to measure the grain size of pearlite in the rolling direction, the grain size of pearlite in the rolling direction can be assumed to be approximately equivalent to the ferrite grain diameter $d$ as shown in Fig. 19, which is the close up as an example of $\mathrm{F}$ in Fig. 5. In addition, it can be expected that almost all micro-cracks initiated at the ferrite-pearlite boundary were propagated though the inside of the pearlite band, as described in Section 3.2.2. It can be therefore assumed that the size of pearlite grain in the rolling direction is almost equivalent to the major axis of micro-crack $a$.

The results in the above present study were obtained by using a sample of the typical low carbon steel described in Section 2. Although the different tendency from the result in Fig. 17 might be obtained for high carbon steels due to the reversal of mutual size relationship between ferrite and pearlite gains, it can be expected that the result in Fig. 17 is applicable to the arbitrary low carbon ferrite-pearlite steels with a similar tendency on the mutual size relationship between ferrite and pearlite gains. It is because the size of the pearlite grain in the rolling direction is assumed to be close to that of ferrite grains as described in Fig. 19, so that

Table 4. Representative cumulative probabilities of aspect ratio of micro-cracks.

\begin{tabular}{cccc}
\hline Cumulative probability & $5 \%$ & $50 \%$ & $95 \%$ \\
\hline Aspect ratio & 0.285 & 0.493 & 0.866 \\
\hline
\end{tabular}

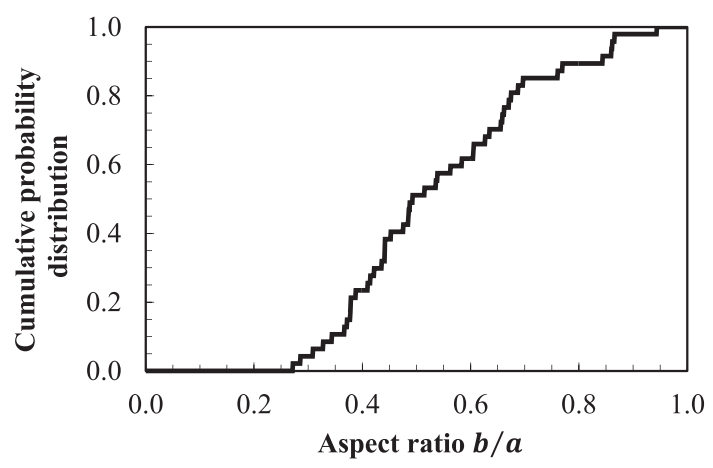

Fig. 18. Aspect ratio of micro-cracks.

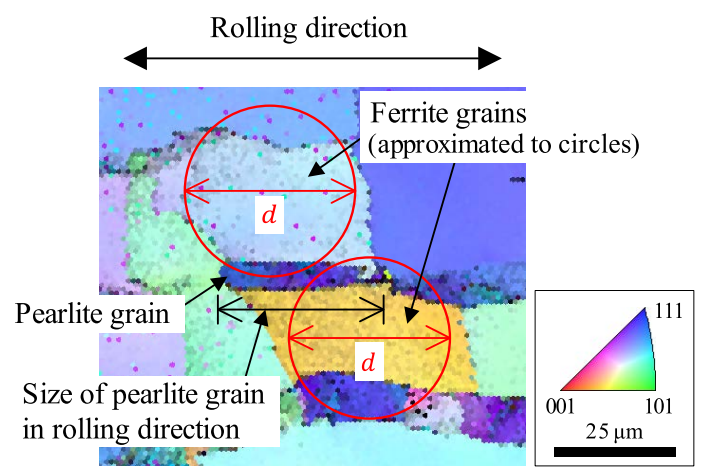

Fig. 19. A typical comparison between pearlite grain size in rolling direction and ferrite grain diameter (Close up of $F$ in Fig. 5). (Online version in color.) 
the major axis of the micro-crack in the pearlite grain is consequently close to the ferrite grain size.

According to the above discussion, it is suggested that it is essential for quantification of the fracture behaviors to take into account the distributions of the size and shape of the micro-cracks as well as the relationship between microcracks and microstructures.

\section{Discussion for Fracture Initiation Modeling}

In the fracture process of the steel having ferrite-pearlite microstructures as shown in Fig. $2{ }^{31)}$ it is found in Section 3 that the shape of a micro-crack gives an influence on fracture condition in the stage (II), which is the propagation of the crack in pearlite grain into ferrite matrix. That is, the results of the observation in Section 3 showed a probability that the shape of a micro-crack can be approximately quantified by the sizes of ferrite grain and pearlite band thickness. In this section, we propose a model to relate microstructures of ferrite-pearlite steel to the fracture stress, which is one of the most essential factors to determine fracture toughness. The model is based on the results of 3D observation shown in Section 3. The effectiveness of the proposed 3D model is discussed by comparing with the conventional 2D model proposed by Hiraide et al., ${ }^{31)}$ which was based on results of the conventional 2D observation and the simplified microcrack model.

\subsection{Conventional Model ${ }^{31)}$}

Based on the 2D observations of the micro-cracks in ferrite-pearlite steels, Hiraide et al. formulated the fracture stress as the fracture condition of the stage (II), related with the microstructural factors. ${ }^{31)}$ They assumed a shape of cross section of pearlite grain to be an ellipse. The major axis and minor axis of the ellipse corresponded with neighbor ferrite grain diameter $d$ and pearlite band thickness $t$, respectively. A schematic of the model is shown in Fig. 19(a).

A length of micro-crack $b$ was calculated as that of a segment along the $\{110\}$ plane where the maximum resolved shear stress acts, expressed as

$$
b=\frac{t}{\sqrt{1-\sin \theta^{2}\left\{1-(d / t)^{2}\right\}}}
$$

where $\theta$ is the angle between a crack and the minor axis of the ellipse (see Fig. 19(a)).

It is difficult to estimate the depth of the crack in 2D observation. Hiraide et al. thus simply assumed the shape of the micro-crack to be a circle. ${ }^{31)}$ The fracture stress $\sigma_{\mathrm{f}(2 \mathrm{D})}$ of the circle crack in solid was calculated based on the Griffith theory, as ${ }^{44)}$

$$
\sigma_{\mathrm{f}(2 \mathrm{D})}=\sqrt{\frac{\pi E \gamma}{\left(1-v^{2}\right) b}}
$$

where $E$ is a Young's modulus, $v$ is a Poisson ratio and $\gamma$ is effective surface energy a propagation of crack at a pearlite grain into ferrite matrix. ${ }^{26)}$

\subsection{Proposed Model}

As presented in the results of the $3 \mathrm{D}$ observation on the micro-cracks in the ferrite-pearlite steel in Section 3, the shape of micro-crack could be modeled as an ellipse. According to the results in Fig. 17, the distribution of the major axis of crack $a$ was good agreement with that of the ferrite grain diameter $d$. On the other hand, the distribution of the minor axis of crack $b$ was an intermediate between those of the ferrite grain diameter $d$ and pearlite band thickness $t$.

Based on the fact, the shape of a pearlite grain is assumed as an oblate spheroid whose major axis and minor axis correspond with $d$ and $t$, respectively, as shown in Fig. 19(b). If a micro-crack is formed through at the center of a spheroid, this assumption is consistent with the observation results that the distribution of $a$ was coincident with that of $d$ and the distribution of $b$ was an intermediate between the distributions of $d$ and $t$. As a result, the shape of the micro-crack can be approximated as an ellipse corresponding to those of observation results obtained in Section 3.

The fracture stress of the ellipse micro-crack is formulated as below. The stress intensity factor $K_{\mathrm{I}}$ at the point $\mathrm{P}$ on the crack front of angle $\varphi$ from the major axis is expressed as (see Fig. 19(b)) $)^{45)}$

$$
K_{\mathrm{I}}(\varphi)=\frac{\sigma \sqrt{\pi b}}{S(a, b)}\left(\sin \varphi^{2}+\frac{b^{2}}{a^{2}} \cos \varphi^{2}\right)^{\frac{1}{4}}
$$

where $\sigma$ is a remote applied stress perpendicular to the crack surface. $S(a, b)$ is a function of $a$ and $b$, expressed as

$$
S(a, b)=\frac{\pi}{2} \int_{0}^{\frac{\pi}{2}} \sqrt{1-\left(1-\frac{b^{2}}{a^{2}}\right)^{2} \sin \psi^{2}} d \psi
$$

A fracture initiates at the point of the maximum $K_{\mathrm{I}}$, which is obtained at $\varphi=\pi / 2$. In addition, the fracture stress $\sigma_{\mathrm{f}(3 \mathrm{D})}$ is defined as the value of $\sigma$ when the maximum $K_{\mathrm{I}}$ reaches the local fracture toughness $K_{\text {Ic }}$. Thus,

$$
K_{\mathrm{Ic}}=\frac{\sigma_{\mathrm{f}(3 \mathrm{D})} \sqrt{\pi b}}{S(a, b)}
$$
$\operatorname{as}^{44)}$

The critical energy release rate $\mathcal{G}_{\mathrm{c}}$ is expressed by $K_{\mathrm{Ic}}$,

$$
\mathcal{G}_{\mathrm{c}}=\frac{K_{\mathrm{Ic}}^{2}}{E^{\prime}}
$$

where $E^{\prime}$ is the effective Young's modulus expressed as $E^{\prime}=$ $E /\left(1-v^{2}\right)$ due to plain strain condition. $\mathcal{G}_{\mathrm{c}}$ is also expressed by $\gamma$, as

$$
\mathcal{G}_{\mathrm{c}}=2 \gamma
$$

According to Eqs. (5), (6) and (7), the fracture stress of the ellipse crack $\sigma_{\mathrm{f}(3 \mathrm{D})}$ is given as

$$
\sigma_{\mathrm{f}(3 \mathrm{D})}=S(a, b) \sqrt{\frac{\pi E \gamma}{\left(1-v^{2}\right) b}}
$$

Equation (8) is coincident with Eq. (2) when $a=b$.

\subsection{Comparison between Two Models}

Figure 20 shows the difference of the shape of microcrack in pearlite grain between the conventional and pro- 


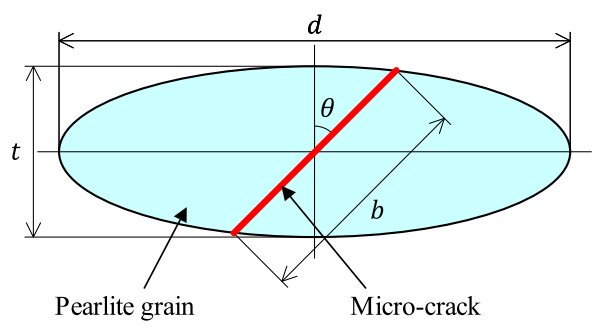

(a) Conventional model [29] (based on 2D observation)

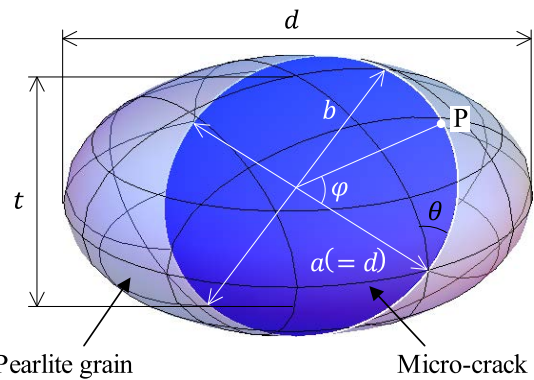

(b) Proposed model (based on 3D observation)

Fig. 20. Description of micro-crack in pearlite grain. (Online version in color.)

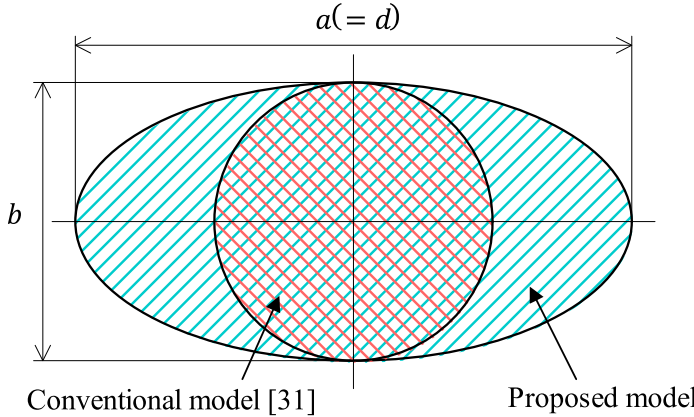

Fig. 21. Difference of crack shapes between the conventional and the present models. (Online version in color.)

posed models presented in Section 4.1 and Section 4.2, respectively.

Figure 21 shows the comparison between the fracture stresses $\sigma_{\mathrm{f}(2 \mathrm{D})}$ (for conventional model shown in Eq. (2)) and $\sigma_{\mathrm{f}(3 \mathrm{D})}$ (for proposed model shown in Eq. (8)). In this graph, the horizontal axis is normalized as an aspect ratio of crack $b / a$. It is noted that the respective results of $\sigma_{\mathrm{f}(2 \mathrm{D})}$ and $\sigma_{\mathrm{f}(3 \mathrm{D})}$ in the vertical axis are also normalized by $\sigma_{\mathrm{f} 0}$, which is defined as $\sigma_{\mathrm{f}(2 \mathrm{D})}$ and $\sigma_{\mathrm{f}(3 \mathrm{D})}$ with circle crack of diameter $a$. As a result, it is found that there was a remarkable difference between the values of the conventional $2 \mathrm{D}$ and proposed $3 \mathrm{D}$ models. In particular, it is expected from the relationship between fracture stress and fracture toughness that the fracture toughness of the conventional 2D model is much higher than that of the proposed 3D one.

To investigate in more detail the difference of the proposed 3D model from the conventional 2D model, the ratio of the fracture stress $r_{\mathrm{f}}\left(=\sigma_{\mathrm{f}(3 \mathrm{D})} / \sigma_{\mathrm{f}(2 \mathrm{D})}\right)$ is shown in Fig. 22. The aspect ratios $b / a$ for the cumulative probabilities of $5 \%$, $50 \%$ and $95 \%$, which were observed in the actual ferritepearlite steel described in Table 4 in Section 3, are also shown in the graph, respectively. In particular, the values of $\sigma_{\mathrm{f}(3 \mathrm{D})}$ for $50 \%$ and $5 \%$ cumulative probabilities of $b / a$ in the actual micro-crack shape are less than those of $\sigma_{\mathrm{f}(2 \mathrm{D})}$ by $23.2 \%$ and $30.7 \%$, respectively. These differences are a significant meaning for the actual use of the structural steels, as mentioned above in Fig. 20. That is, it is expected that the fracture toughness of the conventional $2 \mathrm{D}$ model is $20-30 \%$ higher than that of the proposed $3 \mathrm{D}$ one. That is, it is suggested that the stress intensity factor of the circle crack of simply assumed conventional model based on the $2 \mathrm{D}$ observation is much lower than that of the accurately proposed ellipse crack model based on the detailed

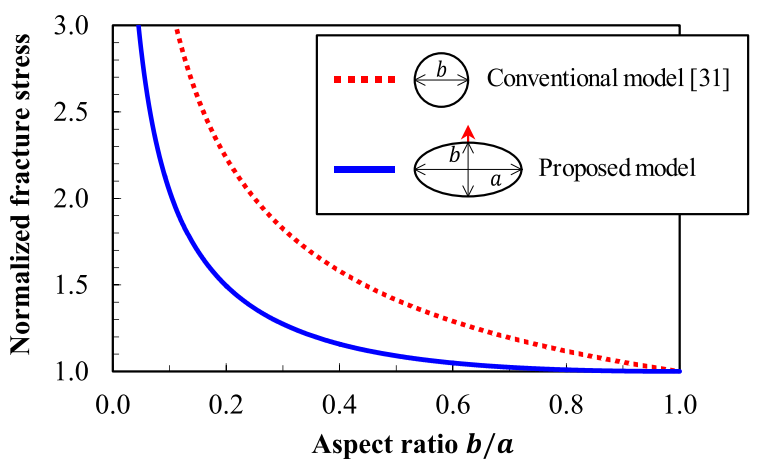

Fig. 22. Comparison of fracture stress relying on crack shapes. (Online version in color.)

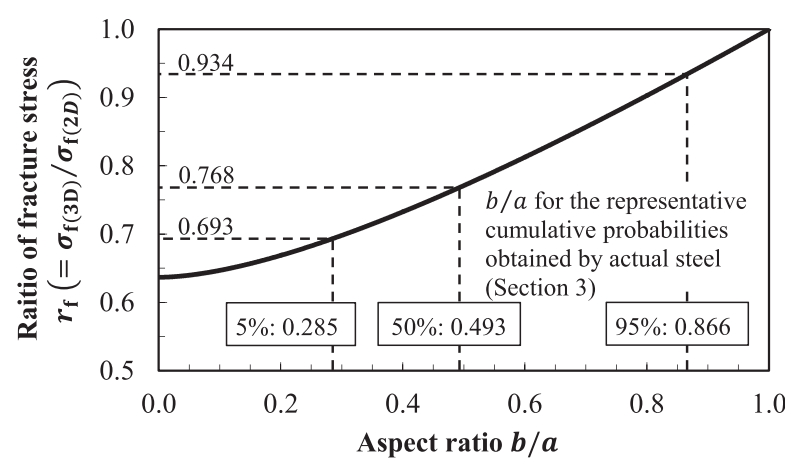

Fig. 23. Normalized fracture stress for ellipse by that for circle.

3D observation. Therefore, the proposed 3D model is the first model providing a potential accurately to quantify the geometric influence factors of microstructures on fracture toughness of ferrite-pearlite steel, which could not be solved by the conventional $2 \mathrm{D}$ model.

\section{Conclusions}

In order to establish a basis to predict cleavage fracture toughness of ferrite-pearlite steels, a two-stage investigation was performed: (i) A foundational characterization of the relationship between micro-cracks and microstructures based on a 3D serial sectioning observation; (ii) A proposal of model to quantitatively relate the geometric influence factors of microstructures to the fracture stress, which is one of the most essential factors to determine the fracture toughness.

The 3D serial sectioning observation was performed in 
order to investigate the relationship between micro-cracks and microstructures. A quasi-static tensile test was conducted using circumferential notched round bar specimen to make a sample to observe micro-cracks. In the $3 \mathrm{D}$ serial sectioning observation, two types of micrographs before and after nital etching were taken to obtain 3D images of micro-cracks and microstructures, respectively. As a result of superposition of both the 3D images of micro-cracks and microstructures, it is found that most of the micro-cracks were across pearlite bands and the others were not across the pearlite bands but all the micro-cracks were commonly initiated at the boundaries between ferrite and pearlite. It indicated that the micro-crack initiates at the boundary between ferrite and pearlite and then stably propagates into inside of the pearlite grain. The shapes of the respective micro-cracks of the 3D images were approximated as ellipses. The results of the quantification showed that the distribution of major axis of micro-crack was close to that of the ferrite grain diameter and the distribution of miner axis was an intermediate between the distributions of ferrite grain diameter and pearlite band thickness. Although the above results were obtained by using a sample of the typical low carbon steel, it is expected to be applicable to arbitrary low carbon ferrite-pearlite steels because the size of the pearlite grain in the rolling direction is consequently close to that of ferrite grains for low carbon ferrite-pearlite steels.

We then proposed a model to relate microstructures of ferrite-pearlite steel to the fracture stress, based on the above $3 \mathrm{D}$ observation results. In the model, the shape of a pearlite grain was assumed as an oblate spheroid whose major axis and minor axis corresponding with ferrite grain diameter and pearlite band thickness, respectively. The oblate spheroid assumption is consistent with shape and size of the approximated ellipse micro-crack formed in the pearlite grain as well as the $3 \mathrm{D}$ observation results. The fracture stress evaluated by the proposed 3D model was compared with that of the conventional $2 \mathrm{D}$ observation based model. It is shown that the fracture stresses corrected by the proposed $3 \mathrm{D}$ model were $20-30 \%$ less than those evaluated by the conventional $2 \mathrm{D}$ model under the aspect ratio of shape for micro-cracks observed in the actual steel. This means that the fracture toughness of the conventional model is evaluated much higher than that of the proposed model due to essential difference on accuracy of modeling between conventional and proposed models. The proposed $3 \mathrm{D}$ model is the first model providing a potential accurately to quantify the geometric influence factors of microstructures on fracture toughness of ferrite-pearlite steel, which could not be solved by the conventional 2D model. Therefore, we can give a valuable basis to develop an accurate fracture toughness prediction model of ferrite-pearlite steel based on the $3 \mathrm{D}$ observation.

\section{Acknowledgements}

The present study was financially supported by ISIJ Research Promotion Grant and Ishihara/Asada Grant. The steel used in the present study was provided from Nippon Steel \& Sumitomo Metal Corporation. The authors gratefully acknowledge them.

\section{REFERENCES}

1) D. A. Curry and J. F. Knott: Met. Sci., 12 (1978), 511.

2) W. C. Leslie: The Physical Metallurgy of Steels, McGraw-Hill, New York, (1981), 621 .

3) G. T. Hahn: Metall. Trans. A, 15A (1984), 947.

4) T. Lin, A. G. Evans and R. O. Ritchie: Metall. Trans. A, 18A (1987), 641.

5) M. S. Bingley: Mater. Sci. Technol., 17 (2001), 700.

6) A. Ghosh, A. Ray, D. Chakrabarti and C. L. Davis: Mater. Sci. Eng. A, 561 (2013), 126.

7) T. Tagawa, Y. Kayamori and H. Hira: Eng. Fract. Mech., 77 (2010), 3077.

8) F. M. Beremin: Metal. Mater. Trans. A, 14 (1983), 2277.

9) A. Peneau: Int. J. Fract., 138 (2006), 139.

10) A. Andrieu, A. Pineau, J. Besson, D. Ryckelynck and O. Bouaziz: Eng. Fract. Mech., 95 (2012), 102.

11) ISO 27306: 2009, Metallic Materials-Method of Constraint Loss Correction of CTOD Fracture Toughness for Fracture Assessment of Steel Components.

12) ASTM E1921: 2015, Standard Test Method for Determination of Reference Temperature, to, for Ferritic Steels in the Transition Range.

13) G. Qian, V. F. González-Albuixech and M. Niffenegger: Eng. Fract. Mech., 136 (2015), 15.

14) H. Mimura: Fatigue Fract. Engng. Mater. Struct., 18 (1995), 699.

15) G. Bernauer, W. Brocks and W. Schmitt: Eng. Fract. Mech., 64 (1999), 305.

16) S. R. Bordet, A. D. Karstensen, D. M. Knowles and C. S. Wiesner: Eng. Fract. Mech., 72 (2005), 435.

17) S. R. Bordet, A. D. Karstensen, D. M. Knowles and C. S. Wiesner: Eng. Fract. Mech., 72 (2005), 453.

18) C. Rugieri: Int. J. Fract., 164 (2010), 231

19) J. Hohe, V. Hardenacke, S. Luckow and D. Siegele: Eng. Fract. Mech., 77 (2010), 3573.

20) A. Martin-Meizoso, I. Ocana-Arizcorreta, J. Gil-Sevillano and M. Fuentes-Prez: Acta Metall. Mater., 42 (1994), 2057.

21) A. Lambert-Perlade, A. Gourgues, J. Besson, T. Sturel and A. Pineau: Metal. Mater. Trans. A, 35 (2004), 1039.

22) K. Shibanuma, S. Aihara and K. Suzuki: Eng. Fract. Mech., 151 (2016), 324.

23) K. Shibanuma, S. Aihara and K. Suzuki: Eng. Fract. Mech., 151 (2016), 341

24) K. Shibanuma, S. Aihara and S. Ohtsuka: ISIJ Int., 54 (2014), 1719.

25) N. J. Petch: Acta Matall, 34 (1986), 1387.

26) J. I. San Martin and J. M. Rodriguez-Ibabe: Scr. Mater., 40 (1999), 459.

27) L. E. Miller and G. C. Smith: J. Iron Steel Inst., 208 (1970), 998.

28) Y. J. Park and I. M. Bernstein: Metall. Trans. A, 10A (1979), 1653.

29) A. Valiente, J. Ruiz and M. Elices: Eng. Fract. Mech., 72 (2005), 709.

30) K. Shibanuma, Y. Nemoto, T. Hiraide, K. Suzuki and S. Aihara: ISIJ Int., 57 (2017), 365

31) T. Hiraide, K. Shibanuma and S. Aihara: Tetsu-to-Hagané, 101 (2015), 384

32) M. V. Kral, M. A. Mangan, G. Spanos and R. O. Rosenberg: Mater. Charact., 45 (2000), 17.

33) J. E. Spowart: Scr. Mater., 55 (2006), 5.

34) D. J. Rowenhorst, A. Gupta, C. R. Feng and G. Spanos: Scr. Mater., 55 (2006), 11.

35) Y. Adachi, S. Morooka, K. Nakajima and Y. Sugimoto: Acta Mater., 56 (2008), 5995.

36) K. Fujisaki, H. Yokota, H. Nakatsuchi, Y. Yamagata, T. Nishikawa, T. Udagawa and A. Makinouchi: J. Microsc., 237 (2010), 89.

37) Y. T. Wang, Y. Adachi, K. Nakajima and K. Sugimoto: Acta Mater., 58 (2010), 4849

38) K. Fujisaki, N. Yamashita and H. Yokota: Precis. Eng., 36 (2012), 315 .

39) OIM Analysis Ver. 6.1, EDAX Inc., Mahwah, New Jersey, (2011).

40) R. T. DeHoff: Trans. TMS-AIME, 224 (1962), 474.

41) SIMULIA Abaqus Analysis User's Manual Version 6.14, Dassault Systemes, Vélizy-Villacoublay, France, (2014).

42) Genus 3D User's Manual, Nakayamadenki, Fukuoka, (2015).

43) Avizo User's Guide 9.0, FEI Company, Hillsboro, Oregon, (2015).

44) T. Anderson: Fracture Mechanics, 3rd ed., CRC Press, FL, (2005).

45) H. Tada, P. C. Paris and G. R. Irwin: The Stress Analysis of Cracks Handbook. ASME Press, New York, (2000). 